\title{
The Challenges Moutai Faces When Developing Its UK Market
}

\author{
Feng Li \\ Wenhua College, Wuhan, China \\ Email: shurigt@126.com
}

Received 6 October 2014; revised 10 November 2014; accepted 20 November 2014

Copyright (C) 2014 by author and Scientific Research Publishing Inc.

This work is licensed under the Creative Commons Attribution International License (CC BY). http://creativecommons.org/licenses/by/4.0/

(c) (i) Open Access

\begin{abstract}
As Chinese government has been started a movement that encourages consumers to save more and fight against waste, the sales of Chinese spirits have dropped off in domestic markets. In order to increase sales and brand equity in the world alcohol industry, the Chinese spirits suppliers have to explore new markets and find opportunities in the US and Europe. Some famous liquor's brands, such as Moutai, have already put more emphasis on overseas markets than before and aim to outsource more products to increase the market share. Therefore, this paper aims to find barriers for Moutai to enter into the UK market, identify its target customers, find strategic solutions to penetrate into the UK market and achieve its market goals.
\end{abstract}

\section{Keywords}

\section{Chinese Spirits, Penetrating Strategies, Drinking Culture}

\section{Introduction}

Liquors have played an important role in Chinese history for a long time; one of the most famous liquor brands is Maotai. It is sophisticated made and need to be brewed for a long time. To be specific, Maotai is made by sorghum and brewed by premium wheat, accompanied with fine water, proper soil and pleasant weather in Maotai Town. Moreover, Maotai-flavor liquor is the best example of Chinese liquors, with 52 - 54 percent alcohol content by volume.

Kweichow Moutai Winery established in 1951, it was named as China Kweichow Moutai Winery Co., Ltd. through successful system transformation in 1997. In 1999, China Kweichow Moutai Winery Co., Ltd., together with China National Research Institute of Food \& Fermentation and other 7 units established Kweichow Moutai Co., Ltd. In August 2001, Kweichow Moutai stock was listed in Shanghai Stock Exchange; in December 2011, the company was renamed as China Kweichow Winery (Group) Co., Ltd. [1]. 
In 1915, it won the gold medal for Panama Pacific International Exposition in America and was known as one of the three major liquors of the world together with Cognac of France and Scotch whisky. Over nearly 100 years, it has successively obtained various international gold medals for 15 times, holding the host of championship of famous liquor evaluation in China for many consecutive years.

However, the golden time for the development of Chinese spirits industry has passed away since 2013. This is mainly due to the fact that the government sets up mind and takes some actions to combat corruption, leading to the decreasing demand of spirits for official business use. The market performance of Chinese liquors has suffered a drastic decrease for continuously three seasons in 2014; even the representative of this industry, Maotai, need to face the truth. The turnover and net income have decreased with $0.99 \%$ and $3.4 \%$ separately, which is the situation Maotai meets for the first time [2]. Recently, the restriction of the consumption of public funds on three major private purposes, which are cars, banquets and overseas visits, is highly supported by the public. The local governments established official documents to limit the official consumption on the spirits; the development of liquor market is therefore estimated to be decreased in the future. Hence, the premium liquors will suffer this change of political trend for a long time [3]. In such situation, these high-end liquor brands have to seek for opportunities in order to overcome the difficulties in main markets and figure out new marketing strategies for further development.

Even though globalisation has exhibited a huge threat to local companies and led to fierce competition, it has also provided more opportunities for them. As well as long-term strategic planning, an open multi-cultural setting also should be considered. In order to maintain its current advantages in the alcohol industry and realise new objectives in the future, Moutai has put great effort into extending its businesses in the global market. As the UK alcoholic drinks market is forecasted to have a value of $\$ 69.3$ billion, an increase of $1.3 \%$ compared with 2012, it cannot be ignored. Therefore, this paper will analyse the challenges in the UK market and provides appropriate recommendations.

\section{Target Market}

The market for premium spirits in the UK is promising. Penetration levels are high despite the fact the alcohol consumption in the UK is slow but steadily declined and any permanent shift will be short, which is a double-edged sword to new comers. On one hand, the new brand can be easily introduced to the market; on the other hand, the advantages won't be permanent if the company cannot respond fast to the market. In addition, the current trend in the UK spirits market is influenced by the constant move to higher price segments and rapidly increased interest in imported brands. However, cheaper brands have suffered the most in the recession; British consumers who have cut down the amount of alcohol they drink are still willing to pay more for premium quality drinks. Age is also a crucial factor that should be taken into consideration. People aged 35 - 64 drink the most in terms of premium alcohol and have more experience with different styles of alcohol and therefore they have the confidence to customise. They are highly educated, better travelled and more adventurous and prefer world-class brands with complex tastes and a greater story.

According to an official report, Moutai is a top-quality liquor brewed with the distillate of five grains with both refined and popular tastes As a premium liquor, Moutai's history spans over one hundred years and has a strong influence in every aspect of Chinese culture. Normally Moutai is drunk at banquets and often sent as gifts to individuals who are highly respected in their relevant fields. Therefore, Moutai is the symbol of success in Chinese culture and Moutai Group sets their target customers as people who have high social status.

Therefore, the characteristics behind Moutai can cater for the demand of those who are aged 35 - 64 and are prepared to pay a premium for quality and a product with a long history in the UK market.

\section{Analysis of Key Challenges}

\subsection{Different Drinking Culture in the UK}

In comparison with British drinking culture, the aim of China's drinking culture is not to get people drunk as soon as possible [4]. People tend to drink small amounts of alcohol over a long period of time. Once people start drinking, it is not considered socially acceptable to stop until everybody else has, the consequence of doing so would be to lose "face". This is due to the fact that "face" can be viewed as one's public self-image and people from low uncertainty avoidance countries like China are afraid of losing face, which also means losing reputa- 
tion [5]. An important part of Chinese drinking culture is the business banquet; people drink baijiu in order to communicate with representatives from other companies. Additionally you are there to represent your company, if one were to back out, the boss and whole company will lose face.

However, there is no "losing face" in British drinking culture. Moutai therefore cannot instil the concept of "face" into British drinking culture. The British drinking culture can be seen to be too excessive, which shows $50 \%$ of consumers drink alcohol "once a week" or "at least twice a week or more". Traditionally, alcohol has been used as a stress reliever to relax and unwind after a tough day's work, which has particularly been the case during the recessions.

However, the drinking culture has experienced some recent changes; consumers drink at home more frequently and less than one fifth of consumers drink to get drunk. British alcoholic consumption has declined since 2004 as consumers cut down their drinking amount for the sake of health or economic or lifestyle changes. In addition, societal changes have caused the UK pub industry to become establishments that are more suitable for families, women and casual dining in order to stop the shift to drinking at home (30\%). Therefore, different drinking culture and its new shift will impede the development of Moutai and force the group design products that are able to adapt to the British drinking culture.

\subsection{Fierce Competition among Premium Alcohol Industries in the UK}

Although the United Kingdom has experienced an economic downturn, premium drinks still attract the richer and recession-weary consumers. In addition, most alcoholic drinks markets have proved to be resilient in recent years, attracting new consumers to the premium class regardless of their declining deposable incomes. However, it has become more difficult to cater for their tastes as they reassess their consumption of premium drinks and ask for tangible differences in terms of taste when they purchase premium products. Although there are consumers who mix up their categories of drinks for certain situations or when they want to try new kinds of drinks, such as cocktails, most customers still choose their favourite ones without specific reasons. Among all the drinks, lager is the most popular one. This is followed by white and red wine, white spirits and cider. In addition, according to Table 1, in terms of the UK spirits market category segmentation, whiskey and vodka constitute the most, with $39.4 \%$ and $25.5 \%$ respectively. The figure for other spirits remains lower than $10 \%$. Therefore, it is hard for Moutai to cater for everyone's taste and compete with drinks that have high market share.

Moreover, the brands that have effectively balanced accessibility with an air of exclusivity have been successful in recent years. Also, there are two main ways in which a large number of operators achieve effective outcomes of refreshing their brand images. Many consumers are able to remain demanding when they choose which brands they should buy, regardless of economic downturn. This is particularly prevalent when the drinks mean more than which should be. According to the Market line, Table 2 illustrates that Diageo plc accounts for the largest UK spirits market share at $26.6 \%$ whereas other operators constitute lower than $10 \%$. It is important to note that Diageo plc has taken full control of Chinese luxury baijiu brand-shuijingfang and sells it to European countries. Therefore, Moutai has to face competitive competitors who occupy a majority market share and have an abundance of experience of how to manage premium brands in the UK market.

Table 1. United Kingdom spirits market category segmentation: \$ billion, 2012.

\begin{tabular}{cccc}
\hline Category & $\mathbf{2 0 1 2}$ & $\mathbf{\%}$ \\
\hline Whisk(e)y & 6.6 & 39.4 \\
Vodka & 4.3 & 25.5 \\
Liqueurs & 1.6 & 9.7 \\
Rum & 1.3 & 7.6 \\
Brandy & 0.9 & 2.3 \\
Specialty spirits & 0.4 & 10.3 \\
Other & 1.7 & $100 \%$ \\
Total & 16.8 & 2.3 \\
\hline
\end{tabular}

Source: Marketline. 
Table 2. United Kingdom spirits market share: \% share, by volume, 2012.

\begin{tabular}{cc}
\hline Company & \% Share \\
\hline Diageo plc & $26.6 \%$ \\
Glen Catrine Bonded Warehouse Ltd. & $9.3 \%$ \\
Bacardi Limited & $5.9 \%$ \\
Brown-Forman Corporation & $4.4 \%$ \\
Other & $53.8 \%$ \\
Total & $100 \%$ \\
\hline
\end{tabular}

Source: Marketline.

\subsection{Trade Barriers}

Due to the economic downturn in the UK, many consumers reconsider what constitutes their values and replace purchasing luxury goods with more reasonable products with cheaper prices. Consumers' interest in luxury items has fallen from 2007 to 2012 constantly with notably less consumers willing to buy quality goods and those which constitutes beauty in daily life. They do not purchase non-essential items and claim that they enjoy good quality goods with economical prices. This may lead to less demand for Moutai, which defines itself as a luxury spirits brand.

In addition, it is said that the UK has a serious alcohol problem that covers many patterns of drinking and ages. The UK government has decided to use licensing laws and tariff laws to reduce crimes that are caused by people who like binge drinking [6]. Taking the tariff law as an example, the tax for local spirits is £26.81 per litre, while the imported drinks need to submit $£ 28.22$ per litre. These differences can be seen as trade barriers that also can be applied to protect local brands and reduce the consumption of certain spirits [7]. This may increase the cost of Moutai's development in the UK market. Another notable example is that after successful entry into WTO, China takes alcohol as general products while western countries regard alcohol as special products which require more tax, which means foreign alcohol can easily export to China, while it is complicated and hard to export to other countries [8]. This might increase the cost and place obstacles on the development of Moutai's globalisation process.

\section{Strategies in Terms of the Key Challenges}

In terms of the product dimension, Moutai's drinks can take suggestions as followed. First, the R\&D department of Moutai group should conduct research as how to make their drinks healthier and can perfectly cater for the tastes for British people. This is due to the fact that even the UK has experienced serious economic recession, consumers are still demanding, they require more tangible differences in taste when purchase premium drinks. What's more, limited editions and innovative flavour has become the most effective methods that can refresh their brand images. Moreover, a more moderate and healthy attitude has emerged and nearly 70\% consumers said that they do not like the feeling of losing control, which suggests a new trend for manufacturing lower alcohol drinks. And drinks with lower alcohol content can enjoy a lower tax rate. Secondly, Moutai group should change the packages in terms of different usage of its products in order to rebuild its profile and attract more consumers. This is due to the fact that consumers nowadays are more likely to adopt immediate and tangible factors such as stylish packaging that are eye-catching and attractive to define a premium spirit.

In addition, Moutai group should consider how to make consumers have easy access to its products and adopt effective distribution channels to sell. First, Moutai should put priority to supermarkets because supermarkets have the highest exposure rate to consumers and consumers purchase most alcohols in supermarkets as well. Second, Moutai group should cooperate with famous corporations who have strong influence and know what British people attitudes toward drinking is and how to propose effective promotion activities. Taking Diageo, the alcohol company that has the biggest market share in British alcohol industry as an example, it bought the luxury baijiu brand "shuijingfang" and full control over it, and has sold shuijingfang successfully to the British ultra-premium supermarket. What's more, marketing agency also can be taken into consideration in order to tap its 
British marketing know-how to promote. Thirdly, as a premium liquor brand, Moutai should cooperate with famous transportation companies, such as Virgin, then Moutai should provide their products in the first class in order to match a high-end definition and tap into use of resources of people who enjoy the first-class service. Last but not least, Moutai should cooperate with high-end restaurants and pubs which are still the main consuming places of alcohol. This can improve its coverage over the drinking market.

However, Moutai group shouldn't reduce its products' price as it has a long brand history of nearly 100 years and can provide quality liquor to satisfy consumers. The pricing strategy Moutai should adopt is to use its outstanding quality of products and services to differentiate from products from other brands. This is also due to the fact that even the British economy has experienced a downturn and consumers drink less alcohol than they used to be; however, they are still increasingly willing to pay more for the quality of alcohol. It is also interesting to note that it is the cheaper brands that have suffered the most in the economic recession.

There are various marketing strategies for Moutai to choose. First, attending the global alcohol exhibition to exhibit their products in order to increase exposure. Therefore, more consumers who are interested in alcohol can have a clear idea of Moutai's products. Secondly, it is recommended for Maotai to adapt online platforms to find opportunities and markets for its products. In July 2013, Maotai held a press conference with the largest online spirits supplier Winebibber to announce their strategic cooperation; Winebibber will also take charge of the whole product line of Maotai in the future. In addition, these products will be distributed to other ten online platforms that cooperated with Winebibber as well [9]. Thirdly, adopting celebrity endorsement strategies to enhance Moutai's brand image. As sponsorship, celebrity endorsements and leveraging heritage are additional strategies which some operators are using to convey their premium qualities. Kim II-sung, a famous politician of North Korea, also likes drinking, especially the Maotai, Chairman Mao therefore sent Maotai as the gift to him before. After that, Maotai has been a must in presents that Chinese government sent to the government of North Korea [10].

In the end, this news was reported all around the world, thereby enhancing Moutai's brand image in a very effective way. Fourth, free educational activities can be hold to teach people from the UK of Moutai's history and how to taste Moutai's products. Consumers had little idea of what premium drinks actually are and why should buy them. In such context, campaigns such as educating consumers and convincing them of the premium credentials of brands should be well utilised to support engagement. Fifth, Moutai should sponsor charitable organisations or students in universities in order to improve its self-image and conduct its social role at the same time. Sixth, Moutai should hire professional team to make a short video that introduces Moutai and its products' differentiation from other spirits through social media in order to establish its own value and improve brand recall in the UK alcohol market.

As a new entry enterprise in the UK spirits market, a conceptual store is strongly recommended to open as to provide a place where people can have easy access to Moutai’s products and culture. Trial products are provided in the store for consumers who show great interests on them. This is the same with the conceptual store of digital brands that arouse many people's interests and help increase the sales as well.

\section{Conclusion}

The analysis above attempted to show the target market of Moutai group in the UK market, what challenges it might face when Moutai enters into this market and what solutions Moutai can adopt in order to address all the problems. The analysis of the challenges is conducted on the base of the theory of PEST analysis while the strategies mentioned are based on the marketing theory of 7Ps. The target customers of Moutai are people who are middle-aged and have enough incomes to consume regardless of the economic downturn. This paper also concludes that Moutai should take cultural differences, fierce competition among premium alcohol brands in the UK market and also trade barriers that Moutai might face when exports its products into consideration. These factors will hinder the way of Moutai's development in target market if this group cannot take them seriously in terms of the UK context. The strategies aim to solve the problems caused by different drinking cultures and social trends. The position and characters of products should all be fixed to cater for the UK drinkers' preferences. In addition, different distribution channels should be considered as to provide wider access of Moutai's products to consumers. Moreover, pricing strategy should follow the principle of making customers realise the underlying value of the products instead of lowering price only. Various promotion methods are also mentioned in order to maximum its exposure to the new market. 


\section{References}

[1] Kweichow Moutai Group (2014) Introduction to Group. http://www.china-moutai.com/publish/portal0/tab276/

[2] Wang, Y. (2014) Moutai Market Price Fell 60\%. http://www.huaxia.com/tslj/flsj/cy/2014/11/4138629.html

[3] Kuanglong (2012) The Alcohol Prohibition Comes Fast and Violent. http://www.21food.cn/html/news/12/718980.htm

[4] Ng, D. (2012) Chinese Drinking Culture. http://www.shanghaiexpat.com/article/chinese-drinking-culture-22349.html

[5] Merkin, R.S. (2006) Uncertainty Avoidance and Facework: A Test of the Hofstede Model. International Journal of Intercultural Relations, 30, 213-228. http://dx.doi.org/10.1016/j.ijintrel.2005.08.001

[6] Mistral, W., Velleman, R., Templeton, L. and Mastache, C. (2006) Local Action to Prevent Alcohol Problems: Is the UK Community Alcohol Prevention Programme the Best Solution? International Journal of Drug Policy, 17, 278-284. http://dx.doi.org/10.1016/j.drugpo.2006.03.006

[7] Partington, G. (2012) Alcohol Duties. http://www.politics.co.uk/reference/alcohol-duties

[8] Suqian (2013) How Chinese Liquor Go Abroad? http://www.tbtguide.com/sxzpt/sqzpt/zdcpks/bj/mygkks/201311/t20131104_49228.html

[9] JY. Kweichow Moutai Cooperate with Winebieer to Explore in the Ecommerce. http://news.ccidnet.com/art/1032/20130710/5057151_1.html

[10] (2014) Fun Stories between Chinese Central Leader and Moutai. http://www.singpao.com/xw/ht/201401/t20140107_482594.html 
Scientific Research Publishing (SCIRP) is one of the largest Open Access journal publishers. It is currently publishing more than 200 open access, online, peer-reviewed journals covering a wide range of academic disciplines. SCIRP serves the worldwide academic communities and contributes to the progress and application of science with its publication.

Other selected journals from SCIRP are listed as below. Submit your manuscript to us via either submit@scirp.org or Online Submission Portal.
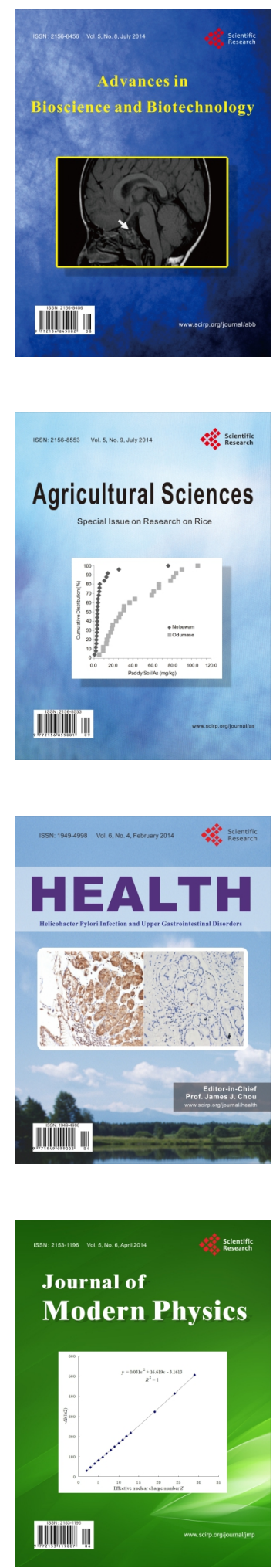
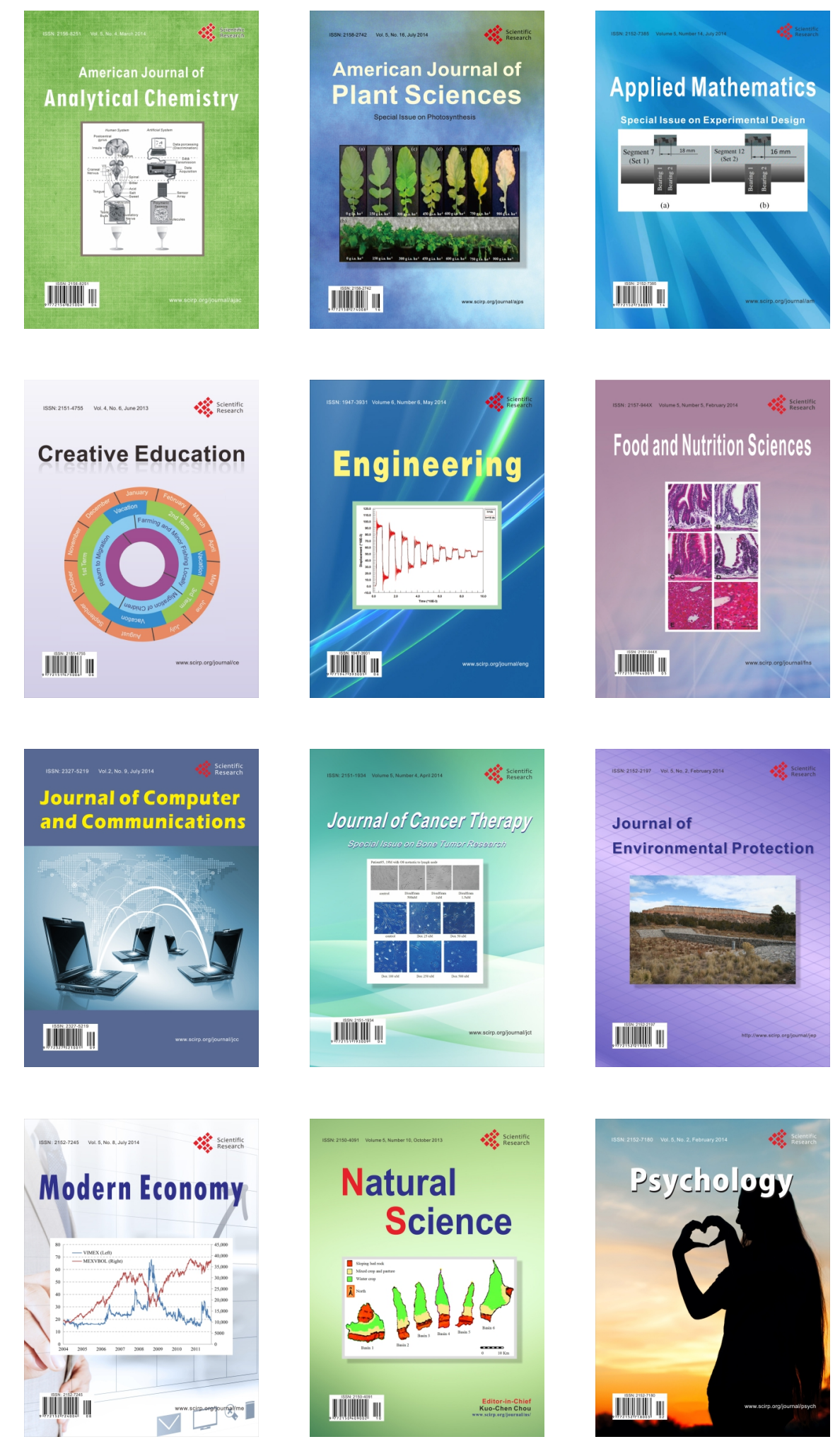